\title{
Homework and Academic Achievement in Latin America: A Multilevel Approach
}

\author{
Rubén Fernández-Alonso 1,2*, Pamela Woitschach³, Marcos Álvarez-Díaz, \\ Andrea M. González-López², Marcelino Cuesta ${ }^{4}$ and José Muñiz ${ }^{4,5}$
}

${ }^{1}$ Department of Education and Culture, Government of the Principality of Asturias, Oviedo, Spain, ${ }^{2}$ Department of Education Sciences, University of Oviedo, Oviedo, Spain, ${ }^{3}$ Department of Educational and Counselling Psychology, and Special Education, Faculty of Education, University of British Columbia, Vancouver, BC, Canada, ${ }^{4}$ Department of Psychology, University of Oviedo, Oviedo, Spain, ${ }^{5}$ Center for Biomedical Research in Mental Health Network (CIBERSAM), Oviedo, Spain

\section{OPEN ACCESS}

Edited by:

Mar Lorenzo Moledo, University of Santiago

de Compostela, Spain

Reviewed by: Jianzhong Xu,

Mississippi State University, United States

Constantino Arce,

University of Santiago

de Compostela, Spain

*Correspondence: Rubén Fernández-Alonso fernandezaruben@uniovi.es

Specialty section: This article was submitted to Educational Psychology, a section of the journal Frontiers in Psychology

Received: 19 November 2018 Accepted: 14 January 2019 Published: 01 February 2019

Citation Fernández-Alonso $R$, Woitschach P, Álvarez-Díaz M, González-López AM, Cuesta M and

Muñiz J (2019) Homework and Academic Achievement in Latin America: A Multilevel Approach. Front. Psychol. 10:95 doi: 10.3389/fpsyg.2019.00095
The relationship between homework and academic results has been widely researched. Most of that research has used English-speaking, European or Asian samples, and to date there have been no detailed studies into that relationship in Latin America and the Caribbean. The aim of this study is to examine the effect of quantitative homework characteristics on achievement in science. The sample comprised 61,938 students at 2,955 schools in the 15 Latin American countries (plus the Mexican state of New Leon) which participated in the Third Regional Comparative and Explanatory Study (TERCE), carried out by the Latin American Laboratory for Educational Quality (LLECE) in 2013. The mean age was 12.42 years old $( \pm 0.94)$. Within each country, three hierarchicallinear models were applied at two levels: student and school. The individual level considered time spent doing homework and the school level considered the amount and frequency of homework assignment. In addition, ten control variables were included in order to control the net effect of the characteristics of the homework on the result. The results confirmed that homework is widely assigned in the Latin American region. At the individual level, time spent on homework had little effect on academic performance, while in the quantitative homework characteristics it was the frequency of homework assignment which demonstrated a clearer effect rather than the amount of homework assigned.

Keywords: homework time, science, academic performance, multilevel models, Latin America

\section{INTRODUCTION}

Student academic performance is influenced by a broad mix of factors which recent research and reviews have identified: opportunities to learn, time on tasks, classroom organization and management, teaching strategies, learner evaluation and feedback, the school environment, and family involvement and expectations about learning (Scheerens and Bosker, 1997; Scheerens et al., 2007, 2013b; Towsend, 2007; Hattie, 2009; Scheerens, 2016; Fernández-Alonso et al., 2017b). In addition, one must consider the contributions of educational theories originating from sociology which confirm that educational success is largely determined by cultural capital and by belonging to dominant groups (White, 1982; Sirin, 2005; Palardy et al., 2015) as well as the theories of learning 
which indicate that neurobiological principles, prior knowledge, and cognitive and affective-motivational personality factors are basic components in the formula for academic success (Shell et al., 2010).

Although homework does not feature in the most important factors in the studies cited above, it has attracted a great deal of attention and been the subject of much research as it is the only teaching factor which is done at home. This characteristic of homework fuels social and family debate, and affects other key variables in school performance, such as family involvement, time on tasks, and learning self-regulation.

Research into homework has progressed toward comprehensive models, which include multiple variables related to the characteristics of the homework, teachers, students and their families (Epstein and Pinkow, 1988; Trautwein et al., 2006; Fernández-Alonso et al., 2016). Nonetheless, the aspect which has been studied the most is the relationship between homework time and school results (Goldstein, 1960; Paschal et al., 1984; Cooper, 1989; Cooper and Valentine, 2001; Trautwein and Köller, 2003; Cooper et al., 2006, 2012; Blazer, 2009; Canadian Council on Learning, 2009; Scheerens et al., 2013a; Fan et al., 2017). Despite the mountains of data gathered so far, the results are far from conclusive, as Scheerens et al. (2013a) clearly indicated. They reviewed 128 independent effects of homework time on individual performance with samples in dozens of countries and found varying results: $32 \%$ of studies showed negative effects, $33 \%$ showed non-significant effects, and $35 \%$ showed positive effects. In short, the debate remains open, and there are no simple, unequivocal answers to key questions like whether homework should be assigned or not, or how much time is most appropriate. This apparent contradiction in results, however, is down to two questions that most of the studies we reviewed had not considered. In the first place, when examining the association between achievement and homework time, much of the research had not addressed a key prior question: Why do some students spend longer than others completing their homework? Flunger et al. (2015) identified five student profiles according to time spent and students' behavior and effort related to homework. In addition, behavior and time spent on homework are conditioned by other variables which also have an influence on school results, such as cognitive capacity, school history, prior knowledge, motivation, sex, age, and sociological factors (De Jong et al., 2000; Trautwein et al., 2002; Trautwein, 2007; Dettmers et al., 2009; Fernández-Alonso et al., 2014, 2015, 2017a). Many studies which have examined the relationship between time spent on homework and school results have not included the effects of these variables in their analyses, hence these apparent contradictions. It is only by controlling for these variables that one may estimate a net effect of the relationship between the quantitative measures of homework and school achievement which is not confounded or affected by other factors.

As indicated by Trautwein and Köller (2003), a significant amount of the research has not addressed the fact that quantitative homework measures are multilevel variables which have different meanings and effects depending on the level being considered. We suppose that the item "How long do you spend on your homework?" when analyzed at the individual level would reflect the student's dedication and work habits. However, if this item is considered at the classroom or school level, it would tend to be an estimation of the amount of homework assigned. In that case it is capturing the effect of the teachers' homework policies, a measure with a completely different meaning. In addition, the effect of these two variables on performance is different, the individual measure has little effect on school results (Farrow et al., 1999; De Jong et al., 2000; Dettmers et al., 2010; Murillo and Martínez-Garrido, 2013; Fernández-Alonso et al., 2014; Núñez et al., 2014), and when it is statistically significant, the effect is negative (Trautwein, 2007; Trautwein et al., 2009; Lubbers et al., 2010; Chang et al., 2014; Fernández-Alonso et al., 2015, 2017a; Núñez et al., 2015). This is consistent with the idea that the time spent on homework by the different types of students is not related to school results (Flunger et al., 2015). Multilevel studies, on the other hand, have found positive effects at class and school level when using variables such as frequency and amount of homework (Farrow et al., 1999; De Jong et al., 2000; Dettmers et al., 2009; OECD, 2013; Fernández-Alonso et al., 2017a). It has also been found that when these two variables go together, the frequency of homework has more explanatory power than homework amount (Trautwein et al., 2002, 2009; Trautwein, 2007; Fernández-Alonso et al., 2014, 2015, 2017a). The classical statistical models do not permit the consideration of student and class level effects at the same time. For that reason, it is necessary to use hierarchical-linear models which can separate the effects of the quantitative homework measures into the two levels noted above.

One of the most hotly debated questions is whether the effect of quantitative homework measures is universal or whether there are factors within educational systems which lead to varying effects in different countries, regions and cultures. The amount of homework tends to be higher in Asian countries, whereas the effect of homework on results seems to be more significant in studies in English-speaking and European samples compared to Asian students (Scheerens et al., 2007, 2013a; Dettmers et al., 2009; Fan et al., 2017). There have not been sufficient studies in Latin America to allow conclusions to be drawn in this regard, although it is worth mentioning the work by Murillo and Martínez-Garrido (2013, 2014), the Third Regional Comparative and Explanatory Study (UNESCO-OREALC and LLECE, 2016a), and the analysis by Dettmers et al. (2009), which includes the three countries in this region which took part in the second edition of the Program for Student Assessment (PISA) in 2003.

Murillo and Martínez-Garrido (2013) used data from nine countries (in addition to Spain), their three level model (studentclass-school) did not segregate data by country. The homework variables were reported by teachers and only considered at school level, with neither the amount, nor the frequency being statistically significant. The only positive relationship was between assigning homework and the result in mathematics, but not in Spanish. In their second study Murillo and MartínezGarrido (2014) once again used measures of frequency and amount of homework reported by teachers, aggregated to schoollevel. They reported descriptive statistics by country, but the 
data were not segregated at that level in the hierarchical-linear model, so there is no way to compare effects between countries. Once again they found that neither variable demonstrated a relationship with reading or mathematics results in students in the 3rd-6th years of primary education. UNESCO-OREALC and LLECE (2016a) did compare effects between countries, but the study only looked at one dichotomous variable at the student level reported by parents, not students: spending $30 \mathrm{~min}$ or more on homework every day (or not). Finally, the study by Dettmers et al. (2009) is the only one which used quantitative measures at two levels (student and school), although only three countries in the region participated. Once controlled for socio-economic level, the results are rather variable: in Mexico they found positive effects at both levels, in Brazil there was only a positive effect at student-level, and in Uruguay there were no significant effects at either level.

In summary, in the Latin American context, there are no studies which systematically compare the effects of quantitative homework measures using multilevel analysis and control variables. The data available are only general, not segregated by country or strata, and only include quantitative measures at a single level (Murillo and Martínez-Garrido, 2013, 2014; UNESCO-OREALC and LLECE, 2016a), and where those conditions are met, the studies include only a limited number of countries from the region (Dettmers et al., 2009). New intercultural analysis models allow much more rigorous comparisons between countries (Byrne and van de Vijver, 2017). In this context, our current study has two objectives. Firstly, to establish the prevalence of homework in Latin America, describing and comparing the quantitative characteristics of homework in the different Latin American countries. Secondly, to estimate the effects of homework time and characteristics of homework assignment (frequency and amount) on school results, adjusting the analysis models according to the socio-demographics of the students, schools, and countries.

\section{MATERIALS AND METHODS}

\section{Participants}

The sample population was defined as those students in the 6th grade of compulsory education in 2013 in the 15 participating Latin American countries and the Mexican state of New Leon. In each country the sample was selected following a twostage stratified cluster method (OECD, 2009; Joncas and Foy, 2012). In the first stage, schools were selected with a probability proportional to their size, and in the second stage a complete class-group was selected from each school, giving a sample of more than 67,000 students. In this current study we excluded students lacking information in the science test, leading to a final sample made up of 61,938 students from 2,955 schools, representing a population of almost 9 million students. The mean age of the students was 12.42 years old with a standard deviation of 0.94 . Over two thirds (69.4\%) attended state schools, $65.8 \%$ attended an urban school; $49.6 \%$ were girls, and $81.9 \%$ were in the school year corresponding to their age, meaning that the remaining $18.1 \%$ had repeated at least one school year at the time of the test.

\section{Instruments}

Two types of instrument were used in the study: (a) tests of academic knowledge, from which we constructed the dependent variable in the study; (b) questionnaires about context for the students, their families, the teachers, and school management, from which we extracted the variables of interest and control variables for our study, with the exception of the relative levels of wealth in each country. The tests were taken during the TERCE evaluation program run by the United Nations Educational, Scientific and Cultural Organization (UNESCO) whose databases are freely available for secondary analysis (UNESCO-OREALC, 2016).

\section{Tests of Academic Performance}

Students completed a battery of tests evaluating reading, mathematics and science, in this study we decided to use the science results as a dependent variable. The science test was produced from a table of specifications organized into five domains and three cognitive processes (UNESCO-OREALC, 2016). It contained 92 items, mostly multiple-choice, grouped in six blocks which were distributed in six test booklets following a matrix design (Fernández-Alonso and Muñiz, 2011). Each student completed one test booklet containing 31 to 33 items they had to answer in $60 \mathrm{~min}$. The items were adjusted to the Rasch model using the Winsteps program (Linacre, 2005). Each student's score was calculated via the methodology of plausible values, which is the most effective for recovering population parameters in evaluations of education systems (Mislevy et al., 1992; OECD, 2009; von Davier et al., 2009) In TERCE, the individual scores were estimated by combining students' item responses with information from various co-variables which functioned as imputation factors, they were expressed on a scale with a mean of 700 points and standard deviation 100 (UNESCOOREALC and LLECE, 2016b).

\section{Control Variables}

When the dependent variable is school performance, it is necessary to include control variables to avoid overestimating the effects of the variables of interest (Fernández-Alonso et al., 2017b). We chose seven control variables from those available in TERCE, all of which are important in the prediction of academic achievement (Liu and Whitford, 2011; UNESCO-OREALC and LLECE, 2016a; Woitschach et al., 2017). Four describe student socio-demographic characteristics: Gender ( 1 = female); Indigenous ( 1 = member of indigenous population); In paid work ( 1 = works and is paid for that work); and Student's Socioeconomic and cultural level (SEC), a standardized index created by TERCE composed of 17 items about parents' levels of education, type of work, family income range, amenities and services in the area where they live, and availability of reading material at home. The values of Cronbach's alpha for this index range between 0.8 and 0.9 depending on the country (UNESCO-OREALC, 2016). The remaining three variables refer to previous school history and the student's learning resources: Repetition ( $1=$ the student has 
repeated a year during their schooling); Textbook ( $1=$ the student has a science textbook); and Notebook ( $1=$ the student has a school notebook).

We used three variables to describe the social and demographic context of the schools, two were dichotomous: School Type ( 1 = private school) and whether a school was Rural. The third variable was the School socioeconomic and cultural level, which was the mean of the student SEC in that school.

\section{Homework Variables}

The questionnaire about student context contained two multiple choice items that were used to construct the variables of interest. Item 1 asked how many days a week do you study or do homework? with response options between 0 and 7 . Item 2 asked how long do you spend doing homework on the days when you study? and had four options: (a) I don't study; (b) less than $1 \mathrm{~h}$ a day; (c) between 1 and $2 \mathrm{~h}$; (d) more than $2 \mathrm{~h}$. The responses were coded as 0,30 , 90 , and $150 \mathrm{~min}$, respectively.

These items were used to construct four variables: Does no homework (NoHW), a dichotomous variable where 1 indicates students who do not do homework; Homework time (HWTime), the mean daily minutes spent doing homework calculated as follows: HWTime $=$ Item $1^{*}$ Item $2 / 7$. HWTime was squared in order to add a quadratic element to the regression (HWTime_2). Teachers' homework policies were described with two variables: The amount of homework (HWAmount), the mean homework time per school; and Frequency of homework assignment (HWFreq), the mean number of days in a school that students do homework.

\section{Procedure}

The cognitive tests were applied by expert personnel who were not employed by the school being tested. Tests were carried out on 2 days, the first day for reading and writing, and the second for mathematics and science. The tests for each subject took between 45 and $60 \mathrm{~min}$, with a 30-min break in the middle; following that, after a 15-min break, the student context questionnaires took about $45 \mathrm{~min}$ to complete. The questionnaires for the schools, teachers and families were distributed on the first day, and collected at the end of the second day. UNESCO ethical guidelines were followed, and the families of the students selected to participate in the evaluation were informed about the study by the school administrations, and were able to choose whether those students would participate in the study or not.

\section{Data Analysis}

The first step in the analysis was to calculate the descriptive statistics for all variables. Following that, for each country three random-intercept hierarchical-linear models were created with two levels: student and school. The modeling strategy was as follows: first produce a null model without predictors to check the distribution of variance in each level. The second model included the four homework variables, and the third model added the control variables described previously. We used the maximum likelihood estimation method with robust standard errors using the HLM 7.01 program (Raudenbush et al., 2011). In all analyses we used the weightings provided by TERCE which were designed so that each country, regardless of size, would have an equal contribution in the analysis of results (UNESCOOREALC, 2016), with the sum total of weights in each country being equivalent to 5000 students.

The amount of missing data in the variables ranged from 2 to $12 \%$. We used a two-step strategy to recover missing data. Firstly, the incomplete cases were imputed with the mean of the subject, then the completely missing data were recovered using the iterative EM method with auxiliary variables in the Missing Value Analysis module of SPSS 24. Fernández-Alonso et al. (2012) found that this two-step strategy produces the best recovery of population data in studies with this (non-random) type of missing data and levels of missing data similar to those in TERCE.

\section{RESULTS}

Table 1 shows the data related to the first research objective, the two basic characteristics of homework assignment habits in each country.

The median number of days doing homework (between 4 and 5 in almost all countries) indicates that Latin American teachers set homework most days of the week. The median is less than 4 in only two cases (Costa Rica and Chile). For the combined TERCE data the estimated amount of homework is a little more than $50 \mathrm{~min}$ a day, the equivalent of a weekly volume of a little more than $6 \mathrm{~h}$. However, there are huge variations between countries. For example, homework in the Dominican Republic requires $3.5 \mathrm{~h}$ a week more than in Chile. The final column shows the percentage of students who do not do homework. The correlation between this percentage and the amount of homework by country is negative $\left(r_{\mathrm{xy}}=-0.66\right)$, in other words countries with a smaller amount of homework tend to have a higher proportion of students who report not doing homework.

In the hierarchical-linear models, the effect of homework is small in Latin American countries (Table 2). In most countries not doing homework has a negative effect, which is statistically significant $(p<0.10)$ in half of the cases. In general the effect of homework time is not significant when considered at the individual level. Of the five statistically significant cases, four were positive and the other negative. Nevertheless, homework time has a small effect. In Ecuador, for example, where the positive effect is largest, once the control variables are added, the model predicts a gain of less than 8 points for each extra hour spent on homework. In the variables which describe the teachers' homework policies, the effect of the frequency of setting homework is positive in most countries and statistically significant in six cases. The amount of homework set exhibits mainly small, negative effects that are not statistically significant. The introduction of control variables in model 3 does not change the direction of the effects but it does mitigate them somewhat, with some cases losing statistical significance.

Table 3 shows the effects of the control variables in model 3. The most determinative variable is socioeconomic level, which is significant in all countries at the individual level, and in almost all countries at school level. Individual variables which 
TABLE 1 | Frequency and amount of homework in Latin American countries.

\begin{tabular}{|c|c|c|c|c|}
\hline \multirow[t]{2}{*}{ Country } & \multirow[t]{2}{*}{ Frequency: days with homework (median) } & \multicolumn{2}{|c|}{ Amount: total daily minutes } & \multirow[t]{2}{*}{ Percentage not doing homework } \\
\hline & & Mean & SEM & \\
\hline Argentina & 4 & 46 & 0.6 & $10 \%$ \\
\hline Brazil & 4 & 45 & 0.5 & $8 \%$ \\
\hline Chile & 3 & 36 & 0.5 & $9 \%$ \\
\hline Colombia & 5 & 57 & 0.5 & $2 \%$ \\
\hline Costa Rica & 3 & 42 & 0.5 & $5 \%$ \\
\hline Ecuador & 5 & 68 & 0.6 & $2 \%$ \\
\hline Guatemala & 5 & 61 & 0.6 & $2 \%$ \\
\hline Honduras & 5 & 60 & 0.6 & $4 \%$ \\
\hline Mexico & 5 & 50 & 0.5 & $4 \%$ \\
\hline Nicaragua & 5 & 60 & 0.5 & $4 \%$ \\
\hline Panama & 5 & 60 & 0.6 & $5 \%$ \\
\hline Paraguay & 4 & 48 & 0.5 & $6 \%$ \\
\hline Peru & 5 & 65 & 0.6 & $2 \%$ \\
\hline Dominican Rep. & 5 & 72 & 0.6 & $4 \%$ \\
\hline Uruguay & 4 & 45 & 0.5 & $11 \%$ \\
\hline New Leon & 5 & 52 & 0.5 & $3 \%$ \\
\hline
\end{tabular}

stand out include repeating school years which has a negative effect in all cases, and availability of basic learning resources (science textbook and school notebook). Once the effect of those variables is controlled for, the variables of gender, being indigenous, and being in work have a smaller effect. A similar situation occurs with the type of school and whether it is urban or rural, which do not demonstrate statistically significant effects in most cases, probably because their effects are overshadowed by the dominance of the effects of the schools' socioeconomic and cultural levels.

Table 4 shows the distribution of the percentage of variance between the two levels of analysis in model 1 (without predictors) and the percentage of that variance explained by models 2 and 3. The percentage of variance in model 1 at school level (L2) indicates that there are significant differences between schools in Latin American countries. One group of countries (Ecuador, Guatemala, Honduras, Nicaragua, Paraguay and Peru) have approximately $50 \%$ of the variance in level 2 , whereas in those cases where the variance is smaller, it is around 20\% (Costa Rica and the Dominican Republic). The results indicate that the percentage of total variance explained by the homework model (model 2) is small, when it is not practically null. In countries where the effect of the homework variables is greater (Argentina and Colombia), the reduction of the total variance is about $7 \%$, but in other cases (Costa Rica, Ecuador, Nicaragua, and Paraguay) the data explain less than $1 \%$ of the total variance. Furthermore, the reduction of variance between students is very small in all cases, which confirms that quantitative homework variables have more impact on the differences between schools than the differences between students. Finally, model 3 indicates that the control variables explain more than half of the variance between schools in most cases and between 15 and 30\% of the total variance.

\section{DISCUSSION AND CONCLUSION}

There are three main reasons justifying interest in this work. The first is its general scientific character: the effect of quantitative homework variables on school results is something which has been widely researched (v. g., Goldstein, 1960; Paschal et al., 1984; Trautwein and Köller, 2003; Cooper et al., 2006, 2012; Trautwein et al., 2006; Scheerens et al., 2013a; Fan et al., 2017) but which has not produced a unanimous answer which is why it is important to add new evidence in that regard. Nonetheless, in the context of Latin America and the Caribbean, a region which represents approximately $8 \%$ of the world's population, there are no studies which focus on systematically analyzing this topic. Research available up to now has not presented data separated by country and has only assessed homework variables in aggregate (Murillo and Martínez-Garrido, 2013, 2014; UNESCO-OREALC and LLECE, 2016a). The second justification is the need to examine whether the results from the research cited above are also found in the Latin American context, which will let us see for the first time the prevalence of homework in those countries, and look at the possible differences between countries. In other words, allow us to analyze the invariance of the relationships in the various Latin American countries (Byrne and van de Vijver, 2017). This study aims to provide transcultural validity by offering data which can be compared with the evidence accumulated by studies in English-speaking, European and Asian populations. Finally, the third reason is that our research may serve as a guide and a stimulus for other similar research in Latin American countries.

If we consider the first objective, we can conclude that more than $90 \%$ of Latin American and Caribbean students do homework to some extent, which is comparable with Western and Asian countries (Dettmers et al., 2009; Fan et al., 2017), 


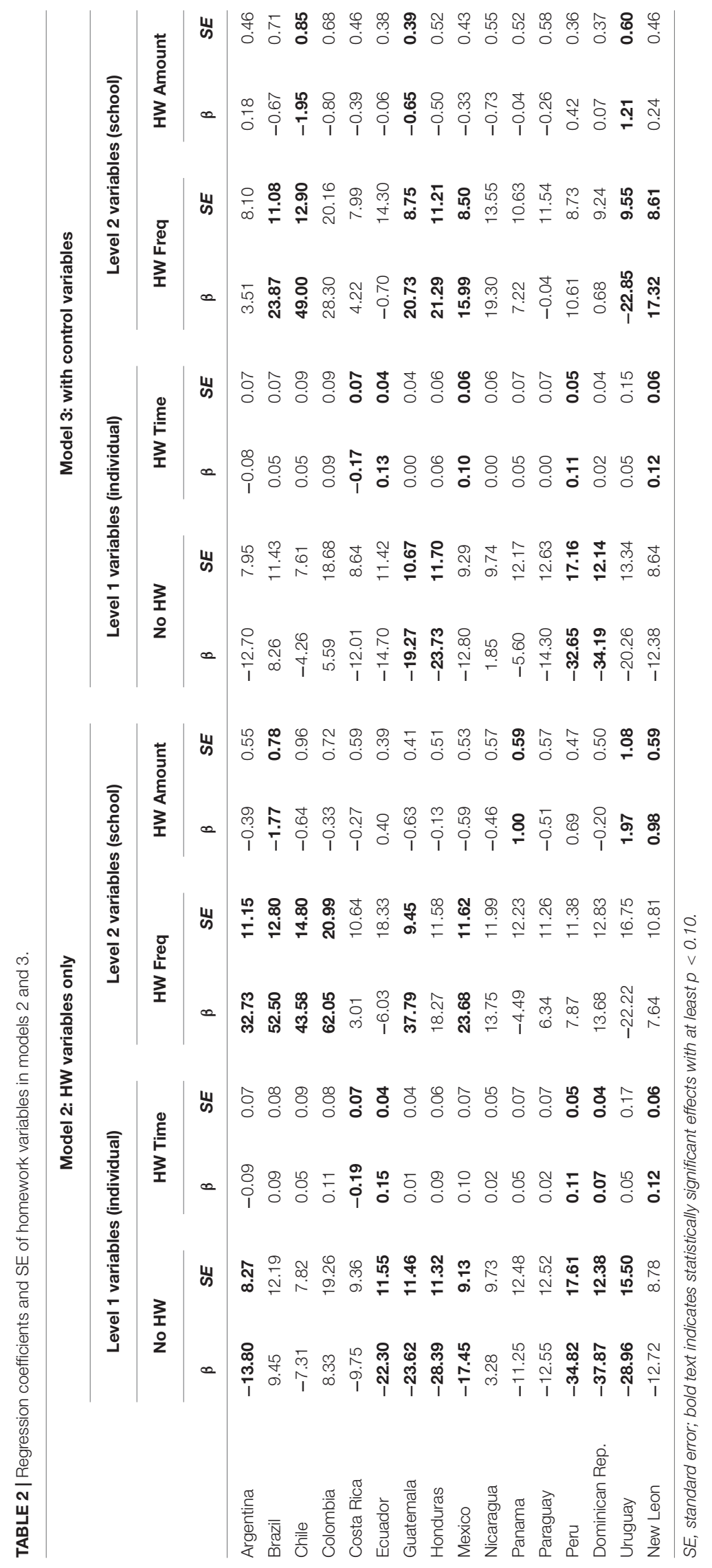




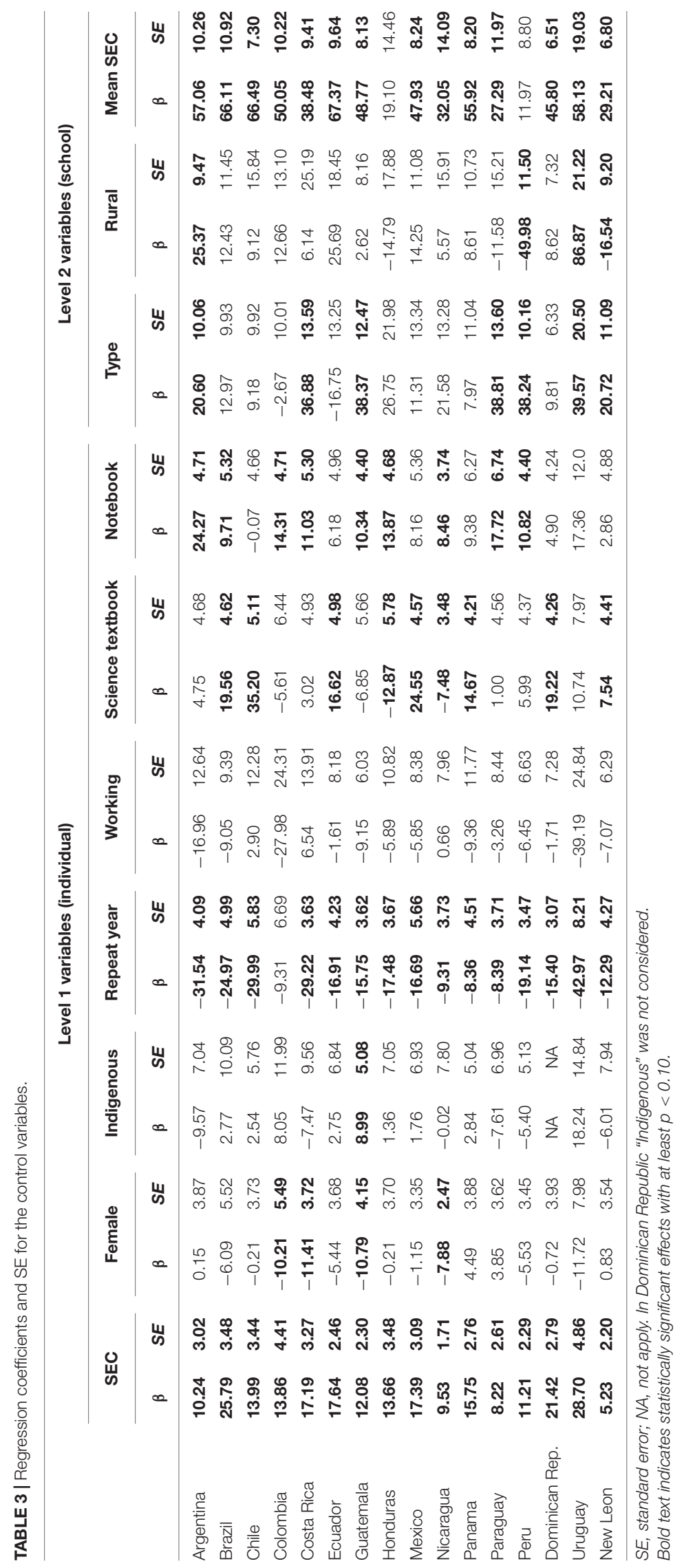


TABLE 4 | Distribution of the variance in model 1 and percentage of variance explained in models 2 and 3.

\begin{tabular}{|c|c|c|c|c|c|c|c|c|c|c|c|}
\hline & \multicolumn{5}{|c|}{ Model 1: without predictors } & \multicolumn{3}{|c|}{ Model 2: homework variables } & \multicolumn{3}{|c|}{ Model 3: all variables } \\
\hline & L1 & L2 & Total & $\%$ Var L1 & $\%$ Var L2 & L1 & L2 & Total & L1 & L2 & Total \\
\hline Argentina & 5663.5 & 3241.0 & 8904.5 & $64 \%$ & $36 \%$ & $0.3 \%$ & $18.0 \%$ & $6.8 \%$ & $5.8 \%$ & $64.4 \%$ & $27.1 \%$ \\
\hline Brazil & 6174.2 & 2878.5 & 9052.7 & $68 \%$ & $32 \%$ & $0.2 \%$ & $15.3 \%$ & $5.0 \%$ & $8.3 \%$ & $72.2 \%$ & $28.6 \%$ \\
\hline Chile & 9021.2 & 3745.2 & 12766.4 & $71 \%$ & $29 \%$ & $0.2 \%$ & $15.4 \%$ & $4.6 \%$ & $4.6 \%$ & $67.0 \%$ & $22.9 \%$ \\
\hline Colombia & 6430.3 & 2637.1 & 9067.4 & $71 \%$ & $29 \%$ & $0.1 \%$ & $23.8 \%$ & $7.0 \%$ & $2.8 \%$ & $52.5 \%$ & $17.3 \%$ \\
\hline Costa Rica & 5786.7 & 1756.0 & 7542.7 & $77 \%$ & $23 \%$ & $0.3 \%$ & $-0.8 \%$ & $0.0 \%$ & $6.6 \%$ & $57.7 \%$ & $18.5 \%$ \\
\hline Ecuador & 4518.4 & 3962.2 & 8480.6 & $53 \%$ & $47 \%$ & $0.6 \%$ & $0.7 \%$ & $0.6 \%$ & $3.9 \%$ & $42.8 \%$ & $22.1 \%$ \\
\hline Guatemala & 3275.0 & 3213.8 & 6488.8 & $50 \%$ & $50 \%$ & $0.1 \%$ & $8.8 \%$ & $4.4 \%$ & $4.1 \%$ & $72.9 \%$ & $38.2 \%$ \\
\hline Honduras & 3306.9 & 3119.8 & 6426.7 & $51 \%$ & $49 \%$ & $0.8 \%$ & $7.2 \%$ & $3.9 \%$ & $3.7 \%$ & $30.2 \%$ & $16.5 \%$ \\
\hline Mexico & 5199.3 & 2484.6 & 7683.9 & $68 \%$ & $32 \%$ & $0.3 \%$ & $5.6 \%$ & $2.0 \%$ & $6.1 \%$ & $61.0 \%$ & $23.8 \%$ \\
\hline Nicaragua & 2586.3 & 2547.0 & 5133.3 & $50 \%$ & $50 \%$ & $0.1 \%$ & $1.2 \%$ & $0.6 \%$ & $1.6 \%$ & $26.6 \%$ & $14.0 \%$ \\
\hline Panama & 5333.2 & 3005.1 & 8338.3 & $64 \%$ & $36 \%$ & $0.0 \%$ & $5.6 \%$ & $2.0 \%$ & $3.7 \%$ & $65.3 \%$ & $25.9 \%$ \\
\hline Paraguay & 3824.2 & 4062.0 & 7886.2 & $48 \%$ & $52 \%$ & $0.0 \%$ & $0.1 \%$ & $0.1 \%$ & $1.8 \%$ & $26.1 \%$ & $14.3 \%$ \\
\hline Peru & 4041.0 & 4049.1 & 8090.1 & $50 \%$ & $50 \%$ & $0.6 \%$ & $12.2 \%$ & $6.4 \%$ & $4.1 \%$ & $54.0 \%$ & $29.1 \%$ \\
\hline Dominican Rep. & 4154.4 & 1035.3 & 5189.7 & $80 \%$ & $20 \%$ & $1.3 \%$ & $10.7 \%$ & $3.2 \%$ & $9.5 \%$ & $65.1 \%$ & $20.6 \%$ \\
\hline Uruguay & 8959.3 & 3117.9 & 12077.2 & $74 \%$ & $26 \%$ & $1.3 \%$ & $7.0 \%$ & $2.8 \%$ & $11.6 \%$ & $81.1 \%$ & $29.6 \%$ \\
\hline New Leon & 5638.0 & 2188.9 & 7826.9 & $72 \%$ & $28 \%$ & $0.2 \%$ & $11.8 \%$ & $3.5 \%$ & $1.2 \%$ & $48.4 \%$ & $14.4 \%$ \\
\hline
\end{tabular}

L1, Level 1 variables (individual); L2, level 2 variables (school).

and which seems to confirm that homework assignment is a universal teaching resource. The amount of daily homework in each region is highly variable. For example, in the Dominican Republic students report spending twice as long on homework as in Chile. Nonetheless, the time spent on homework in most countries ranges between 45 and $60 \mathrm{~min}$ a day, which is in line with what one would expect for students in the 6th grade according to Cooper's (2001) "10 min rule."

Previous evidence from multilevel analyses indicated that the effect of homework time at the individual level is small and when it is statistically significant, this effect is negative (Trautwein, 2007; Dettmers et al., 2010; Núñez et al., 2014, 2015). These results seem to be confirmed in Latin America and the Caribbean, as in the model with control variables only Ecuador, Mexico (including New Leon) and Peru gave results contrary to that hypothesis. In the case with the greatest effect (Ecuador), the model predicts gains of less than $8 \%$ of a standard deviation for each extra hour spent on homework; little yield for the effort and dedication needed.

In general, the quantitative variables describing teachers' homework policies produce expected results, although the proportion of statistically significant effects is rather lower than one might expect based on the evidence available from other contexts. After applying the control variables, only half of the countries demonstrated statistical significance for the frequency or amount of homework set. Nevertheless, these data are consistent with previous research indicating that the frequency of homework seems to have more impact on results than the amount of homework set (Trautwein et al., 2002, 2009; Trautwein, 2007; Fernández-Alonso et al., 2014). These results have clear educational implications for teachers' homework policies, as they seem to indicate that the frequent assignment of homework has more positive effects than assigning large amounts of homework.

It is worth noting that the effects of homework frequency and homework amount on scores in science are closely related as the correlation between these effects is very negative $(r=-0.88)$. This would seem to indicate that in those countries where frequency has less influence, homework amount has a greater effect. The most extreme case is Uruguay, the only country where homework frequency shows a statistically significant negative effect, but one which is compensated for by the opposite effect of homework amount. These data have new educational implications: very large amounts of homework not only seem detrimental (in most countries the effect of homework amount is negative), but there is also evidence indicating that within-class differences between students are greater in those class groups with a larger amount of homework (Fernández-Alonso et al., 2017a).

These results must be interpreted in light of our study's limitations. The most important of which is probably the lack of a measure of prior performance. In the data, the only variable related to school history was the repetition of a school year, which as one might expect, had a negative effect in every case. However, research has repeatedly shown that measures of previous performance are the best predictors in this type of study (Murillo and Martínez-Garrido, 2013; Núñez et al., 2014; Fernández-Alonso et al., 2015). In addition, the statistical models used in this study are correlational and therefore the conclusions cannot be read in causal terms. As Trautwein and Lüdtke (2009) clearly indicated, the word "effect" must be understood as "predictive effect," as it is not possible to establish the direction of the association. Our study predicts achievement in science with generic homework measures. It would have been better 
to employ measures which were specific to the subject being studied (e.g., time spent on science homework, Trautwein and Lüdtke, 2007, 2009). Nevertheless, studies which have looked at the relationship between results in various subjects and specific homework time measures have found similar effect sizes in the subjects they evaluated (Lubbers et al., 2010; Chang et al., 2014). An additional limitation is that although TERCE evaluated two age cohorts: 3rd and 6th year of compulsory education, in the context questionnaire for the 3rd year there was insufficient information to construct variables such as homework time and homework amount. For that reason in this study we only focus on the 6th year sample, something which should be borne in mind when considering the generalizability of the results. Future research must be directed toward including other variables which have been shown to be important. The specification and confirmation of a comprehensive model which addresses student behavior and motivation, homework characteristics, teachers' use of homework, teaching quality, teacher review and feedback, and the role of the family in homework is an unresolved issue in the Latin American context, while there is already evidence of this type available in other regions (Epstein and Pinkow, 1988; Cooper, 1989; Trautwein et al., 2006; Cunha et al., 2018; León et al., 2018).

\section{REFERENCES}

Blazer, C. (2009). Literature Review: Homework. Miami: Miami Dade County Public Schools. Available at: https://files.eric.ed.gov/fulltext/ED536245.pdf

Byrne, B., and van de Vijver, F. (2017). The maximum likelihood alignment approach to testing for approximate measurement invariance: a paradigmatic cross-cultural application. Psicothema 29, 539-551. doi: $10.7334 /$ psicothema2017.178

Canadian Council on Learning (2009). A Systematic Review of Literature Examining the Impact of Homework on Academic Achievement. Available at: http://edu.au.dk/fileadmin/edu/Udgivelser/SystematicReview_ HomeworkApril27-2009.pdf

Chang, C. B., Wall, D., Tare, M., Golonka, E., and Vatz, K. (2014). Relations of attitudes toward homework and time spent on homework to course outcomes: the case of foreign language learning. J. Educ. Psychol. 106, 1049-1065. doi: $10.1037 / \mathrm{a} 0036497$

Cooper, H. (1989). Synthesis of research in homework. Educ. Leadersh. 47, 85-91.

Cooper, H. (2001). The Battle Over Homework: Common Ground for Administrators, Teachers, and Parents. Thousand Oaks, CA: Sage.

Cooper, H., Robinson, J. C., and Patall, E. A. (2006). Does homework improve academic achievement? A synthesis of research, 1987-2003. Rev. Educ. Res. 76, 1-62. doi: 10.3102/00346543076001001

Cooper, H., Steenbergen-Hu, S., and Dent, A. L. (2012). "Homework," in APA Educational Psychology Handbook: Application to Learning and Teaching, Vol. 3, eds K. R. Harris, S. Graham, and T. Urdan (Washington, DC: American Psychological Association), 475-495. doi: 10.1037/ 13275-019

Cooper, H., and Valentine, J. C. (2001). Using research to answer practical questions about homework. Educ. Psychol. 36, 143-153. doi: 10.1207/S15326985EP 3603_1

Cunha, J., Xu, J., Rosario, P., and Núñez, J. C. (2018). Validity and reliability of the parental homework management scale. Psicothema 30, 337-343. doi: 10.7334 /psicothema2017.426

De Jong, R., Westerhof, K. J., and Creemers, B. P. M. (2000). Homework and student math achievement in junior high schools. Educ. Res. Eval. 6, 130-157. doi: 10.1076/1380-3611(200006)6:2;1-E;F130

Dettmers, S., Trautwein, U., Lüdtke, M., Kunter, M., and Baumert, J. (2010). Homework works if homework quality is high: using multilevel modeling to

\section{ETHICS STATEMENT}

This study was carried out in accordance with the recommendations of the United Nations Educational, Scientific and Cultural Organization (UNESCO). All subjects gave written informed consent in accordance with the Declaration of Helsinki.

\section{AUTHOR CONTRIBUTIONS}

RF-A and JM designed the research. RF-A, PW, and AG-L analyzed the data. MÁ-D and MC interpreted the data. RF-A, PW, AG-L, MÁ-D, and MC drafted the paper. JM revised it critically. All authors gave final approval of the version to be published and have ensured the accuracy and integrity of the work.

\section{FUNDING}

This research was funded by the Ministerio de Economía y Competitividad del Gobierno de España. References: PSI201785724-P and BES2012-053488.

predict the development of achievement in mathematics. J. Educ. Psychol. 102, 467-482. doi: 10.1037/a0018453

Dettmers, S., Trautwein, U., and Lüdtke, O. (2009). The relationship between homework time and achievement is not universal: evidence from multilevel analyses in 40 countries. Sch. Effect. Sch. Improv. 20, 375-405. doi: 10.1080/ 09243450902904601

Epstein, J. L., and Pinkow, L. (1988). A Model for Research on Homework Based on U.S. and International Studies. Baltimore, MD: Johns Hopkins University.

Fan, H., Xu, J., Cai, Z., He, J., and Fan, X. (2017). Homework and students' achievement in math and science: a 30-year meta-analysis, 1986-2015. Educ. Res. Rev. 20, 35-54. doi: 10.1016/j.edurev.2016.11.003

Farrow, S., Tymms, P., and Henderson, B. (1999). Homework and attainment in primary schools. Br. Educ. Res. J. 25, 323-341. doi: 10.1080/0141192990250304

Fernández-Alonso, R., Álvarez-Díaz, M., Suárez-Álvarez, J., and Muñiz, J. (2017a). Students' achievement and homework assignment strategies. Front. Psychol. 8:286. doi: 10.3389/fpsyg.2017.00286

Fernández-Alonso, R., Álvarez-Díaz, M., Woitschach, P., Suárez-Álvarez, J., and Cuesta, M. (2017b). Parental involvement and academic performance: less control and more communication. Psicothema 29, 453-461. doi: 10.7334/ psicothema2017.181

Fernández-Alonso, R., and Muñiz, J. (2011). Diseños de cuadernillos para la evaluación de competencias básicas [Booklets design for the assessment of basic competences]. Aula Abierta 39, 3-34.

Fernández-Alonso, R., Suárez-Álvarez, J., and Muñiz, J. (2012). Imputación de datos perdidos en las evaluaciones diagnósticas educativas [Imputation methods for missing data in educational diagnostic evaluation]. Psicothema 24, 167-175.

Fernández-Alonso, R., Suárez-Álvarez, J., and Muñiz, J. (2014). Tareas escolares en el hogar y rendimiento en matemáticas: una aproximación multinivel con estudiantes de enseñanza primaria [Homework and academic performance in mathematics: a multilevel approach with primary school student]. Rev. Psicol. Educ. 9, 15-30.

Fernández-Alonso, R., Suárez-Álvarez, J., and Muñiz, J. (2015). Adolescents' homework performance in mathematics and science: personal factors and teaching practices. J. Educ. Psychol. 107, 1075-1085. doi: 10.1037/edu0000032

Fernández-Alonso, R., Suárez-Âlvarez, J., and Muñiz, J. (2016). Homework and performance in mathematics: the role of the teacher, the family and the student's background. Rev. Psicodidáctica 21, 5-23. doi: 10.1387/RevPsicodidact.13939 
Flunger, B., Trautwein, U., Nagengast, B., Lüdtke, O., Niggli, A., and Schnyder, I. (2015). The Janus-faced nature of time spent on homework: using latent profile analyses to predict academic achievement over a school year. Learn. Instr. 39, 97-106. doi: 10.1016/j.learninstruc.2015.05.008

Goldstein, A. (1960). Does homework help? A review of research. Element. Sch. J. 60, 212-224. doi: 10.1086/459804

Hattie, J. A. C. (2009). Visible Learning: A Synthesis of Over 800 Meta-Analyses Relating to Achievement. London: Routledge.

Joncas, M., and Foy, P. (2012). Sample Design in TIMSS and PIRLS. Available at: http://timssandpirls.bc.edu/methods/pdf/TP_Sampling_Design.pdf

León, J., Medina-Garrido, E., and Ortega, M. (2018). Teaching quality: high school students' autonomy and competence. Psicothema 30, 218-223. doi: 10.7334/ psicothema2017.23

Linacre, J. M. (2005). A User's Guide to WINSTEPS/MINISTEP Rasch-Model Computer Programs (Version 3.55). Chicago, IL: MESA Press.

Liu, X., and Whitford, M. (2011). Opportunities-to-learn at home: profiles of students with and without reaching science proficiency. J. Sci. Educ. Technol. 20, 375-387. doi: 10.1007/s10956-010-9259-y

Lubbers, M. J., Van Der Werf, M. P. C., Kuyper, H., and Hendriks, A. A. J. (2010). Does homework behavior mediate the relation between personality and academic performance? Learn. Individ. Differ. 20, 203-208. doi: 10.1016/j.lindif. 2010.01.005

Mislevy, R. J., Beaton, A. E., Kaplan, B., and Sheehan, K. M. (1992). Estimating population characteristics from sparse matrix samples of item responses. J. Educ. Meas. 29, 133-161. doi: 10.1111/j.1745-3984.1992.tb00371.x

Murillo, F. J., and Martínez-Garrido, C. (2013). Homework influence on academic performance. A study of Iberoamerican students of primary education. Rev. Psicodidáctica 18, 157-171. doi: 10.1387/RevPsicodidact.6156

Murillo, F. J., and Martínez-Garrido, C. (2014). Homework and primary-school students' academic achievement in Latin America. Int. Rev. Educ. 60, 661-681. doi: 10.1007/s11159-014-9440-2

Núñez, J. C., Suárez, N., Rosário, P., Vallejo, G., Valle, A., and Epstein, J. L. (2015). Relationships between perceived parental involvement in homework, student homework behaviors and academic achievement: differences among elementary, junior high and high school students. Metacognit. Learn. 10, 375406. doi: 10.1007/s11409-015-9135-5

Núñez, J. C., Vallejo, G., Rosário, P., Tuero, E., and Valle, A. (2014). Student, teacher, and school context variables predicting academic achievement in biology: analysis from a multilevel perspective. Rev. Psicodidáctica 19, 145-171. doi: 10.1387/RevPsicodidact.7127

OECD (2009). PISA Data Analysis Manual: SPSS, 2nd Edn. Paris: OECD Publishing.

OECD (2013). PISA 2012 Results: What Makes Schools Successful? Resources, Policies and Practices, Vol. 4. Paris: OECD Publishing.

Palardy, G., Rumberger, R., and Butler, T. (2015). The effect of high school socioeconomic, racial, and linguistic segregation on academic performance and school behaviors. Teach. Coll. Rec. 117, 1-52.

Paschal, R. A., Weinstein, T., and Walberg, H. J. (1984). The effects of homework on learning: a quantitative synthesis. J. Educ. Res. 78, 97-104. doi: 10.1080/ 00220671.1984.10885581

Raudenbush, S. W., Bryk, A. S., Cheong, Y. F., Congdon, R. T., and du Toit, M. (2011). HLM7: Hierarchical Linear and Nonlinear Modeling. Chicago, IL: Scientific Software International.

Scheerens, J. (2016). Educational Effectiveness and Ineffectiveness a Critical Review of the Knowledge Base. Berlin: Springer. doi: 10.1007/978-94-017-7459-8

Scheerens, J., and Bosker, R. J. (1997). The Foundations of Educational Effectiveness. Oxford: Elsevier.

Scheerens, J., Hendriks, M., Luyten, H., Sleegers, P., and Cees, G. (2013a). Productive Time in Education. A Review of the Effectiveness of Teaching Time at School, Homework and Extended Time Outside School Hours. Enschede: University of Twente.

Scheerens, J., Witziers, B., and Steen, R. (2013b). A meta-analysis of school effectiveness studies. Rev. Educ. 361, 619-645. doi: 10.4438/1988-592X-RE2013-361-235

Scheerens, J., Luyten, H., Steen, R., and Luyten-de Thouars, Y. (2007). Review and Meta-Analyses of School and Teaching Effectiveness. Enschede: University of Twente.
Shell, D. F., Brooks, D. W., Trainin, G., Wilson, K. M., Kauffman, D. F., and Herr, L. M. (2010). The Unified Learning Model. Dordrecht: Springer. doi: 10.1007/ 978-90-481-3215-7

Sirin, S. (2005). Socioeconomic status and academic achievement: a metaanalytic review of research. Rev. Educ. Res. 75, 417-453. doi: 10.3102/ 00346543075003417

Towsend, T. (2007). International Handbook of School Effectiveness and Improvement. Dordrecht: Springer. doi: 10.1007/978-1-4020-5747-2

Trautwein, U. (2007). The homework-achievement relation reconsidered: differentiating homework time, homework frequency, and homework effort. Learn. Instr. 17, 372-388. doi: 10.1016/j.learninstruc.2007.02.009

Trautwein, U., and Köller, O. (2003). The relationship between homework and achievement: still much of a mystery. Educ. Psychol. Rev. 15, 115-145. doi: 10.1023/A:1023460414243

Trautwein, U., Köller, O., Schmitz, B., and Baumert, J. (2002). Do homework assignments enhance achievement? A multilevel analysis in 7 th grade mathematics. Contemp. Educ. Psychol. 27, 26-50. doi: 10.1006/ceps.2001.1084

Trautwein, U., and Lüdtke, O. (2007). Students' self-reported effort and time on homework in six school subjects: between-student differences and withinstudent variation. J. Educ. Psychol. 99, 432-444. doi: 10.1037/0022-0663. 99.2.432

Trautwein, U., and Lüdtke, O. (2009). Predicting homework motivation and homework effort in six school subjects: the role of person and family characteristics, classroom factors, and school track. Learn. Instr. 19, 243-258. doi: 10.1016/j.learninstruc.2008.05.001

Trautwein, U., Lüdtke, O., Schnyder, I., and Niggli, A. (2006). Predicting homework effort: support for a domain-specific, multilevel homework model. J. Educ. Psychol. 98, 438-456. doi: 10.1037/00220663.98.2.438

Trautwein, U., Schnyder, I., Niggli, A., Neumann, M., and Lüdtke, O. (2009). Chameleon effects in homework research: the homework-achievement association depends on the measures used and the level of analysis chosen. Contemp. Educ. Psychol. 34, 77-88. doi: 10.1016/j.cedpsych.2008. 09.001

UNESCO-OREALC (2016). Reporte Técnico Tercer Estudio Regional Comparativo $y$ Explicativo. TERCE [Third Regional Comparative and Explanatory Study TERCE Technical Report]. Santiago: UNESCO.

UNESCO-OREALC and LLECE (2016a). Informe de Resultados del Tercer Estudio Regional Comparativo y Explicativo. Factores Asociados [Report of the Third Regional Comparative and Explanatory Study. Effectiveness factors]. Santiago: UNESCO.

UNESCO-OREALC and LLECE (2016b). Informe de Resultados del Tercer Estudio Regional Comparativo y Explicativo. Logros de aprendizaje [Report of the Third Regional Comparative and Explanatory Study. Learning outcomes]. Santiago: UNESCO.

von Davier, M., Gonzalez, E., and Mislevy, R. J. (2009). What are Plausible Values and Why are They Useful? IERI Monograph Series. Issues and Methodologies in Large-Scale Assessments. Available at: http://www.ierinstitute.org/fileadmin/ Documents/IERI_Monograph/IERI_Monograph_Volume_02.pdf

White, K. R. (1982). The relation between socioeconomic status and academic achievement. Psychol. Bull. 91, 461-481. doi: 10.1037/0033-2909.91.3.461

Woitschach, P., Fernández-Alonso, R., Martínez-Arias, R., and Muñiz, J. (2017). Influencia de los centros escolares sobre el rendimiento académico en Latinoamérica [Effects of the schools on the academic achievement in Latinamerica]. Rev. Psicol. Educ. 12, 138-154. doi: 10.23923/rpye2017. 12.152

Conflict of Interest Statement: The authors declare that the research was conducted in the absence of any commercial or financial relationships that could be construed as a potential conflict of interest.

Copyright (C) 2019 Fernández-Alonso, Woitschach, Álvarez-Díaz, González-López, Cuesta and Muñiz. This is an open-access article distributed under the terms of the Creative Commons Attribution License (CC BY). The use, distribution or reproduction in other forums is permitted, provided the original author(s) and the copyright owner(s) are credited and that the original publication in this journal is cited, in accordance with accepted academic practice. No use, distribution or reproduction is permitted which does not comply with these terms. 